\title{
EDITORIAL
}

\section{Attacking the source: anti-PDX-1 responses in type 1 diabetes}

\author{
Yaima Luzardo and Clayton Elwood Mathews
}

Type 1 diabetes (T1D) develops as a consequence of abnormal responses against several selfantigens, eventually leading to the autoimmune attack and destruction of the insulin-producing $\beta$ cells in the pancreas. In this issue of Laboratory Investigation, Li et al propose the transcription factor Pancreatic and duodenal homeobox 1 (PDX-1) as a T1D autoantigen by demonstrating autoreactivity to this pancreas-specific protein in both the NOD mouse model and patients with T1D. Because of the known roles of PDX-1 in pancreatic development as well as $\beta$ cell maintenance and function, targeting of PDX-1 expressing cells may result in the elimination of not only $\beta$ cells but also the progenitor cells required for regeneration of insulin-producing cells.

Laboratory Investigation (2010) 90, 6-8; doi:10.1038/labinvest.2009.121

Department of Pathology, Immunology, and Laboratory Medicine, The University of Florida College of Medicine, Gainesville, FL, USA.

Correspondence should be addressed to: clayton.mathews@ pathology.ufl.edu
T ype 1 diabetes (T1D) is a devastatingly difficult disease, and proper therapy requires frequent blood glucose monitoring, a daily multi-injection insulin regimen, and a high level of patient motivation to achieve tight glycemic control. This disease results from responses of an unbalanced immune system against proteins expressed in the insulin secreting pancreatic $\beta$ cells, leading ultimately to the destruction of these cells, a dearth of insulin secretion, and hyperglycemia. The anti-self or autoimmune responses are against several antigens, including those that are restricted to the $\beta$ cell as well as some extant in a wide variety of cell types.

The response against the autoantigens in T1D is associated with both aberrant cellular as well as humoral responses. Autoantibodies have been used to predict those at risk for T1D development, ${ }^{1-4}$ yet antibodies are not thought to contribute in the pathology of the disease. Serum positivity for a specific antibody is a marker for T-cell activation to the particular antigen. T-cell responses are seen as predictive of eminent risk as these cells are believed to be the final effectors. ${ }^{5}$

Significant similarities are measured in the antigenic responses comparing patient samples to the NOD mouse. The NOD mouse model is the most well-characterized animal in the study of autoimmune diabetes. Although the majority of antigens in diabetes were initially identified from patient samples, recent utilization of the NOD model system has led to the discovery of two antigens, glucose-6-phosphatase, catalytic, 2 (G6PC2) and Dystrophia myotonica-protein kinase (DMPK). ${ }^{6,7}$ Studies have since demonstrated that the islet-restricted antigen G6PC2 is an antigen in T1D patients. ${ }^{8,9}$ In this issue of Laboratory Investigation, Li et al ${ }^{10}$ exploit the NOD mouse system to identify Pancreatic and duodenal homeobox 1 (PDX-1) as an autoantigen and extend the findings to show that sera from patients with T1D have circulating autoantibodies to this antigen as well.

Recently, a multidimensional analysis of microarray data for both the abundance and specificity of transcripts to human pancreas ranked the top 'candidate autoantigens' for T1D diabetes. ${ }^{11}$ Out of the top 68 hits, 14 of the gene products have been reported earlier as autoantigens in T1D. Of interest to this work was the listing of PDX-1 near the top of this list. Li et $a l^{10}$ report that PDX-1 autoantibodies (PAA) were present in roughly half of the NOD females tested. When tested by western blot, sera from both NOD and T1D patients recognize an epitope in the C-terminal portion of PDX-1, whereas human sera recognizes another epitope within amino acids 160-199. Similar to the appearance of insulin autoantibodies (IAA) in the NOD mouse, 
the timing of the humoral response to PDX-1 varied between NOD mice, yet with the small number of animals used in this study it is difficult to determine kinetics of PAA appearance over the spectrum of NOD mice. T cells from NOD mice also responded to the C-terminal epitope, demonstrating the coordinated response between the T and B cells. If these data are corroborated, it would place PAA as relatively equal to IAA for prediction of diabetes in the NOD mouse. Expectantly, forthcoming reports will provide data on kinetics of the anti-PDX-1 antibodies in both female and male mice, as in an earlier study using IAA as a diagnostic marker, ${ }^{12}$ as well as include MHC matched controls, such as the NOR mouse strain, for both antibody and T-cell assays. With the tests for recently identified T1D autoantigens rapidly incorporated into clinical laboratories, the validation of PDX-1 should be swift.

During pancreatic development, transcription factors regulate endocrine $v s$ exocrine cell fate. Most of these factors are members of the homeodomain-containing protein (HD) family, such as PDX-1. PDX-1 expression is first detected on embryonic day (E) 8.5 in the part of the gut epithelium destined to develop into the pancreas, and is then highly expressed in the adult $\beta$ cells. ${ }^{13}$ The role of PDX-1 in development was highlighted in studies showing that targeted mutations of this gene result in agenesis of the pancreas. $^{14,15}$ In addition, a single nucleotide deletion in $P d x-1$ also causes pancreatic agenesis in man. ${ }^{16}$ Conditional $\beta$ cell-specific inactivation of $P d x-1$ during development not only causes early onset diabetes, but also abnormal numbers of other islet cell types. ${ }^{17}$ Adult mice with a disruption of the gene in the differentiated $\beta$ cells failed to maintain glucose homeostasis; ${ }^{18}$ a deficiency that correlated with decreased glucose transporter 2 (Glut2) and insulin expression. ${ }^{18}$ Thus, in addition to its requirement for pancreatic development, PDX-1 expression is indispensable for retaining the insulin-producing $\beta$ cell phenotype.

PDX-1 in the maintenance of $\beta$ cell mass has not been directly demonstrated; nonetheless, a role of PDX-1 has been established for the compensatory expansion of $\beta$ cell mass in metabolic syndrome. ${ }^{19}$ PDX-1 is likely essential for the augmentation of $\beta$ cell mass after injury resulting from partial pancreatectomy and after injection of streptozotocin in mice, rats, and monkeys. $^{20-25}$ Although recuperation from chemically and surgically mediated $\beta$ cell damage requires $\mathrm{PDX}-1$, recovery is not identical for all forms of damage. Mice encoding an FK506inducible transgene for active caspase 8 , the 'PANIC-ATTAC' model, recover from $\beta$ cell apoptosis and the resulting diabetes using $\beta$ cell progenitors that were not PDX-1 positive. $^{26}$ Therefore, for injury models, the cellular source as well as the progenitor cells required for regeneration or recovery remain controversial. ${ }^{22,23,27}$

The role of PDX-1 in $\beta$ cell development and recovery of these insulin-producing cells from injury has major ramifications in strategies to cure T1D. What little we know about this process has been gathered from the NOD model. In prediabetic NOD mice, inflammation in the pancreatic islets (insulitis) is associated with $\beta$ cell proliferation. $^{28,29}$ Indeed, adoptive transfer of splenocytes into immundeficient NOD-Scid mice results in recapitulation of the proliferative process present in NOD mice progressing to spontaneous T1D. Clearly, the replicative capacity of the islet cannot keep pace with the autoimmune destruction and eventually the $\beta$ cell mass drops below the threshold to maintain euglycemia. A failure to significantly expand the $\beta$ cell mass after immunotherapy with anti-CD3, ${ }^{28,30}$ suggests either that after T1D onset $\beta$ cells are significantly dysfunctional through the suppression of PDX-1 expression by hyperglycemia, ${ }^{31}$ the balance of proliferation $v s$ apoptosis is reduced, ${ }^{28}$ or that the progenitor cells required for the regeneration of the islet $\beta$ cells are missing. The data presented by Li et al ${ }^{10}$ may suggest that by targeting PDX-1 the immune system is not only seeking to destroy all $\beta$ cells but also the potential to create insulin-producing cells. Such a vendetta against the $\beta$ cells as well as their progenitors should be seriously considered in the development of a strategy for the prevention or reversal of T1D in man.

\section{ACKNOWLEDGEMENT}

This work was supported by the Juvenile Diabetes Research Foundation, the National Institutes of Health grant R01 DK74656, and the Sebastian Family Endowment for Diabetes Research.

1. Eisenbarth GS, Jeffrey J. The natural history of type 1A diabetes. Arquivos brasileiros de endocrinologia e metabologia 2008;52:146-155.

2. Pietropaolo M, Yu S, Libman IM, et al. Cytoplasmic islet cell antibodies remain valuable in defining risk of progression to type 1 diabetes in subjects with other islet autoantibodies. Pediatr Diabetes 2005;6:184-192.

3. Verge CF, Gianani R, Kawasaki E, et al. Prediction of type I diabetes in first-degree relatives using a combination of insulin, GAD, and ICA512bdc/IA-2 autoantibodies. Diabetes 1996;45:926-933. 
4. Wang J, Miao D, Babu S, et al. Prevalence of autoantibody-negative diabetes is not rare at all ages and increases with older age and obesity. J Clin Endocrinol Metab 2007;92:88-92.

5. Huurman VA, Hilbrands R, Pinkse GG, et al. Cellular islet autoimmunity associates with clinical outcome of islet cell transplantation. PloS One 2008;3:e2435.

6. Lieberman SM, Evans AM, Han B, et al. Identification of the beta cell antigen targeted by a prevalent population of pathogenic CD8+ T cells in autoimmune diabetes. Proc Natl Acad Sci USA 2003;100:8384-8388.

7. Lieberman SM, Takaki T, Han B, et al. Individual nonobese diabetic mice exhibit unique patterns of CD8+ T cell reactivity to three islet antigens, including the newly identified widely expressed dystrophia myotonica kinase. J Immunol 2004;173:6727-6734.

8. Jarchum I, Nichol L, Trucco M, et al. Identification of novel IGRP epitopes targeted in type 1 diabetes patients. Clin Immunol (Orlando, Fla) 2008;127:359-365.

9. Takaki T, Marron MP, Mathews CE, et al. HLA-A*0201restricted T cells from humanized NOD mice recognize autoantigens of potential clinical relevance to type 1 diabetes. J Immunol 2006;176:3257-3265.

10. Li S-W, Koya V, Li Y, et al. Pancreatic duodenal homeobox 1 protein is a novel $\beta$-cell-specific autoantigen for type 1 diabetes. Lab Invest 2009;90:31-39 (this issue).

11. Wenzlau JM, Juhl K, Yu L, et al. The cation efflux transporter ZnT8 (SIc30A8) is a major autoantigen in human type 1 diabetes. Proc Natl Acad Sci USA 2007;104:17040-17045

12. Abiru N, Yu L, Miao D, et al. Transient insulin autoantibody expression independent of development of diabetes: comparison of NOD and NOR strains. J Autoimmun 2001;17:1-6.

13. Guz $Y$, Montminy MR, Stein $R$, et al. Expression of murine STF-1, a putative insulin gene transcription factor, in beta cells of pancreas, duodenal epithelium and pancreatic exocrine and endocrine progenitors during ontogeny. Development 1995;121:11-18.

14. Ahlgren $\mathrm{U}$, Jonsson J, Edlund $\mathrm{H}$. The morphogenesis of the pancreatic mesenchyme is uncoupled from that of the pancreatic epithelium in IPF1/PDX1-deficient mice. Development 1996;122:1409-1416.

15. Offield MF, Jetton TL, Labosky PA, et al. PDX-1 is required for pancreatic outgrowth and differentiation of the rostral duodenum. Development 1996;122:983-995.

16. Stoffers DA, Zinkin NT, Stanojevic V, et al. Pancreatic agenesis attributable to a single nucleotide deletion in the human IPF1 gene coding sequence. Nat Genet 1997; 15:106-110.

17. Gannon M, Ables ET, Crawford L, et al. pdx-1 function is specifically required in embryonic beta cells to generate appropriate numbers of endocrine cell types and maintain glucose homeostasis. Dev Biol 2008;314: 406-417.
18. Ahlgren $\mathrm{U}$, Jonsson $\mathrm{J}$, Jonsson $\mathrm{L}$, et al. beta-cell-specific inactivation of the mouse Ipf1/Pdx1 gene results in loss of the beta-cell phenotype and maturity onset diabetes. Genes Dev 1998;12:1763-1768.

19. Kulkarni RN, Jhala US, Winnay JN, et al. PDX-1 haploinsufficiency limits the compensatory islet hyperplasia that occurs in response to insulin resistance. J Clin Invest 2004;114:828-836.

20. Bottino R, Criscimanna A, Casu A, et al. Recovery of endogenous beta-cell function in nonhuman primates after chemical diabetes induction and islet transplantation. Diabetes 2009;58:442-447.

21. Kritzik MR, Jones $E$, Chen $Z$, et al. PDX-1 and Msx-2 expression in the regenerating and developing pancreas. J Endocrinol 1999;163:523-530.

22. Liu T, Wang CY, Gou SM, et al. PDX-1 expression and proliferation of duct epithelial cells after partial pancreatectomy in rats. Hepatobiliary Pancreat Dis Int 2007;6:424-429.

23. Peshavaria $\mathrm{M}$, Larmie $\mathrm{BL}$, Lausier J, et al. Regulation of pancreatic beta-cell regeneration in the normoglycemic $60 \%$ partial-pancreatectomy mouse. Diabetes 2006;55:3289-3298

24. Takeshita F, Kodama M, Yamamoto $\mathrm{H}$, et al. Streptozotocin-induced partial beta cell depletion in nude mice without hyperglycaemia induces pancreatic morphogenesis in transplanted embryonic stem cells. Diabetologia 2006;49:2948-2958

25. Tiemann K, Panienka R, Kloppel G. Expression of transcription factors and precursor cell markers during regeneration of beta cells in pancreata of rats treated with streptozotocin. Virchows Arch 2007;450:261-266.

26. Wang ZV, Mu J, Schraw TD, et al. PANIC-ATTAC: a mouse model for inducible and reversible beta-cell ablation. Diabetes 2008:57:2137-2148.

27. Nir T, Melton DA, Dor Y. Recovery from diabetes in mice by beta cell regeneration. J Clin Invest 2007;117:2553-2561.

28. Sherry NA, Kushner JA, Glandt $M$, et al. Effects of autoimmunity and immune therapy on beta-cell turnover in type 1 diabetes. Diabetes 2006;55: 3238-3245.

29. Sreenan S, Pick AJ, Levisetti M, et al. Increased beta-cell proliferation and reduced mass before diabetes onset in the nonobese diabetic mouse. Diabetes 1999:48:989-996.

30. Sherry NA, Chen W, Kushner JA, et al. Exendin-4 improves reversal of diabetes in NOD mice treated with anti-CD3 monoclonal antibody by enhancing recovery of beta-cells. Endocrinology 2007;148: 5136-5144.

31. Harmon JS, Gleason CE, Tanaka Y, et al. In vivo prevention of hyperglycemia also prevents glucotoxic effects on PDX-1 and insulin gene expression. Diabetes 1999:48:1995-2000. 